\title{
sciendo
}

\section{Energy Consumption as an Indicator of Hidden Economy: Comparative Analysis}

\author{
Blagica Novkovska \\ Faculty of Economics, University of Tourism and Management, Skopje, \\ Republic of Macedonia \\ Ksenija Dumičić \\ Department of Statistics, Faculty of Economics and Business, University of \\ Zagreb, Zagreb, Croatia
}

\section{Abstract}

Background: Hidden economy presents a major concern for all national economies, particularly for those of developing countries. Objectives: In this work, methods for determination of the size of hidden economy are discussed. Particular attention is devoted to the methods using electricity consumption as an indicator (the Lackó method and the Kaufmann and Kaliberda method). Methods/Approach: The modified Lackó method adapted for a single country and the sophisticated Kaufmann and Kaliberda method have been used. Results: It has been shown that such methods are effective in measurement of the hidden economy extent in small open economies exposed to severe external influences. The article presents results for Macedonia and their comparison with results for Croatia, as a good role-model for other states in Western Balkans. Conclusions: Model methods involving energy consumption are particularly efficient in determination of the size of the hidden economic sector in small open economies as those of the Western Balkan countries.

Keywords: hidden economy, the DYMIMIC method, the Lackó method, the Kaufmann and Kaliberda method, currency demand method, energy consumption elasticity JEL classification: 017

Paper type: Research article

Received: Jan 31, 2018

Accepted: Apr 21, 2018

Citation: Novkovska, B., Dumičić, K. (2018), "Energy Consumption as an Indicator of Hidden Economy: Comparative Analysis", Business Systems Research, Vol. 9, No. 2, pp. 96-107.

DOI: 10.2478/bsri-2018-0022

\section{Introduction}

Hidden economy is particularly significant phenomenon for the modern society. It is important both from the side of its effect on the total economy and from the side of its characterization and analysis (Schneider, 2017).

Hidden economy is generally categorized from the point of view of tax-paying and economic reporting to official institutions. Therefore, this part is not visible to official producers of macro-economic data. Main quantity describing the size of the 
hidden economy is corresponding Gross Domestic Product (GDP) of hidden economy sector, later in this work described as HY. It is usually considered the total Gross Domestic Product (TY) to be composed of the part of regular Gross Domestic Product $(Y)$ and that of hidden economy $(H Y)$, i.e.

$$
T Y=Y+H Y
$$

From the point of view of its characterization, hidden economy presents a big challenge for researchers, since it is not directly measurable quantity. Therefore, various assumptions are to be made before constructing the model for determination of the size of hidden economy, as a measure of its presence and influence on economic activities of the countries.

Hidden economy presents a serious concern for all economies. However, in the case of developing countries this issue becomes rather important both because of the higher extent compared to this in the developed countries and because of negative effects due to the high exposure to external influences that affect the total economy through increasing the level of hidden economy.

\section{Literature review}

For small open economies, as are those of Western Balkans, the issue of determination of the size of hidden economy become more complex, since they are exposed to severe external shocks strongly affecting their economy (Dumicic et al., 2015).

Significant interest between researchers for hidden economy in Macedonia and Croatia resulted in several studies of the phenomenon. Between the works for Croatia we refer to the works from earlier period, such as (Ott, 2003). Recent works (Bejaković, 2017) demonstrate the continuing interest for the problem and the nead for more detailed analyses.

The methods of determination of the hidden economy size are recognized as direct and indirect methods, as given in (Williams et al., 2015) and (Williams et al., 2016). In this paper, some of the most often used indirect methods are listed and focused. The methods using electricity consumption as an indicator (the Lackó method and the Kaufmann and Kaliberda method) are considered separately. After the Tanzi method, introduced in 80-ties of the last century, as described in (Tanzi, 1980) and (Tanzi et al., 1982), the DYMIMIC method, presented in (Schneider et al., 2010), with an application, as given in (Schneider, 2017), is shown. The Tanzi method comparison with others, later introduced, methods is given in (Tanzi, 1999). Further, the Lackó method (Lackó, 2011) and the Kaufman and Kaliberda (1996) method are focused. Finally, an application to hidden economy for two countries, Macedonia and Croatia over the period from 1990 to 2004, follows.

\section{Methodology}

Methods of determination of the size of hidden economy are divided in two groups: direct and indirect methods. Between the direct methods, the method based on statistical surveys is quite often used (Williams et al., 2015; 2016). In this method activities constituting the sector of hidden economy are immediately targeted, but the deficiencies of the method are significant. Namely, due to the nature of the economic activity studied, only partial reporting is expected and the size of the hidden economy estimated by these methods is substantially underestimated. 
Therefore, particular attention is to be paid to indirect methods that do not rely on the reporting by specific subjects (companies or individuals), but on the effects of the hidden economy on the total economy of the country.

\section{The Tanzi method}

First between the indirect methods to be mentioned is the currency demand approach (the Tanzi method) introduced in 1980s (Tanzi, 1980; Tanzi et al., 1982). Later, this method was compared with other newest methods (Tanzi, 1999).

In this method the currency demand is considered to be increased due to the presence of hidden economy, where financial transactions are expected to be mostly done in cash. Therefore, the excess cash flow is to be considered as a measure of the size of hidden economy. The main advantage of this method is that the observed variable represents a financial quantity, and hence the measure for the size of hidden economy is obtained straightforward in units of the national currency. Many authors also nowadays use this method (Ardizzi et al., 2014).

However, there is a substantial deficiency of this method relying in the fact that currency demand is a complex phenomenon involving multiple factors (Takala et al., 2010). Detailed studies on the money demand (Palić et al., 2016) and monetary transmission mechanism in Croatia (Dumičić et al., 2010) support the above finding for the case of Western Balkans.

\section{The DYMIMIC method}

Second, the dynamic multiple indicators multiple causes method (called the DYMIMIC method) is to be regarded (Schneider et al., 2010). This method is rather complex, involving several causes (direct and indirect taxation, state regulation burden, unemployment and GDP) and indicators of the presence and extent of hidden economy (employment, GDP growth and currency change). Delay between the causes and the effect (hidden economy) is taken into account (see Fig. 1).

Figure 1

Diagram of connections between the causes and indicators in the DYMIMIC model

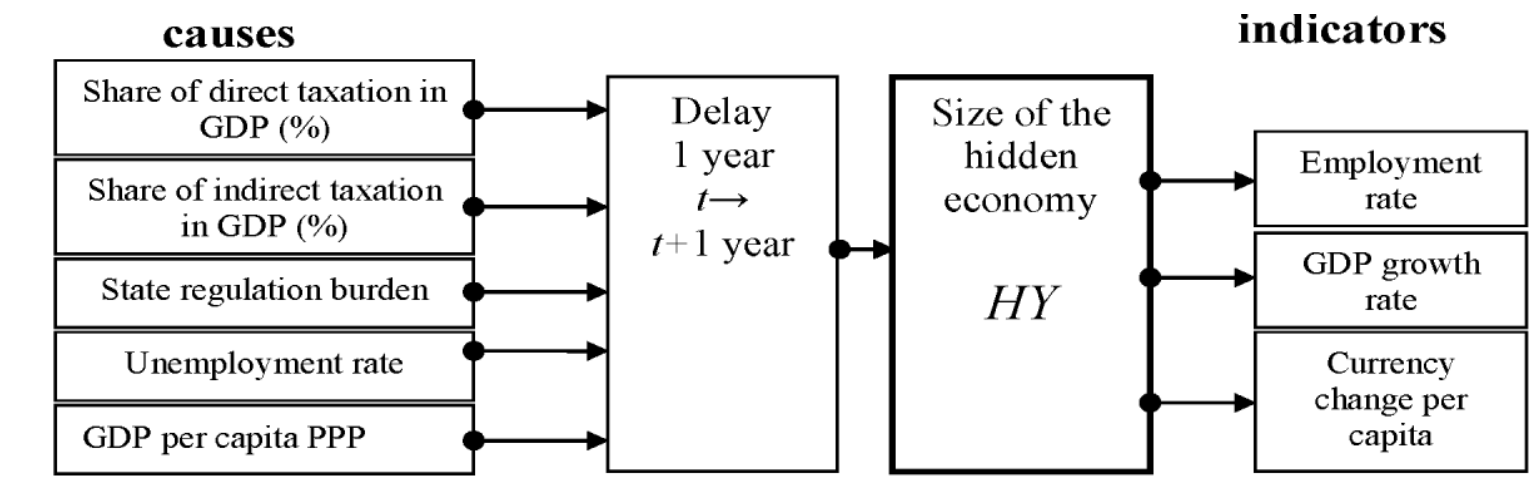

Source: Authors' work

We have previously shown that the above method can be efficiently used to determine the size and the variations of the hidden economy in a small open economy in the case of Macedonia (Novkovska, 2016a).

This method is complex and requires powerful analytical tools for its use (hidden variables and delay between the cause and the effect). However, there are some deficiencies that have to be considered when using it, requiring some precautions. First, even if it is rather complex, there are no strong proofs that it is exhaustive, 
meaning that some important factors can be neglected while using it. Second, even if the delay between the causes and the main consequence is reasonable, its size for 1 year is somehow arbitrarily chosen.

\section{The Lackó method}

Particular attention in this work is devoted to the methods involving energy consumption. In this case, the quantities (indicators) used in determination of the hidden economy are obtained by precise measurements of a real physical quantity.

First we discuss the method where household electricity consumption is used as a main indicator. The household electricity approach, called the Lackó method, (Lackó, 2011), in a cross-country investigation is described by two simultaneous equations:

$$
\ln E_{i}=a_{1} \ln C_{i}+a_{2} \ln P R_{i}+a_{3} G_{i}+a_{4} Q_{i}+a_{5} H Y_{i}+a_{6}+u_{i}
$$

With coefficients $a_{1}>0, a_{2}<0, a_{3}>0, a_{4}<0$ and $a_{5}>0$ and

$$
H Y_{i}=\hat{a}_{1} T_{i}+\hat{a}_{2} S_{i}+\hat{a}_{3} D_{i}
$$

with coefficients $\hat{a}_{1}>0, \hat{a}_{2}<0$ and $\hat{a}_{3}>0$, where: $i$ is an integer number indexing the country, $E_{\mathrm{i}}$ is the electricity consumption per capita in households of the given country, $C_{i}$ is the households real consumption per capita excluding the electricity consumption in the given country in PPP (purchasing power parity) US dollars and PR is the real price of residential electricity for consumption of $1 \mathrm{kWh}$ in PPP US dollars. Further, $G_{i}$ is the number of months needing heating of houses in the given country divided by $12, Q_{i}$ is the share of other energy sources except electricity with respect to all energy sources involved in household energy consumption, HYis the contribution to the GDP per capita from the hidden economy, $T_{i}$ is the share of the sum of taxes for paid personal income, corporate profit and goods and services in GDP, $S_{i}$ is the share of public expenditures for social welfare in GDP, and $D_{i}$ is the percentage ratio of the dependant persons older than 14 as one with the inactive earners number to the number of active persons that earn.

In (Novkovska, 2016b) we have shown that the above method can be adapted to the use for a single country and applied to the case of Macedonia, where significant variations due to external shocks are present. We will discuss these results in next section.

\section{Sophisticated Kaufman and Kaliberda method}

Electricity input method of Kaufmann and Kaliberda (1996), uses a single indicator dependant on hidden economy, the total consumption of electricity in the country $(E)$ in conjunction with the official gross domestic product GDP (Y). In (Novkovska ef al., 2018) we further developed this method using an analytical expression for the size of hidden economy $(H Y)$ for a given year $(t)$ :

$$
H Y(t)=r\left(1-\left(1-\frac{H Y(0)}{r}\right) \frac{Y(t)}{Y(0)}\left(\frac{E(0)}{E(t)}\right)^{1 / \mu}\right)
$$


where $H Y(0)$ is a measure of the extent (size) of hidden economy in the base year ( $n$ $=0$ ), as determined by an independent method. There are two parameters: $\mu$ is the elasticity for electricity consumption $(E)$ with respect to GDP $(Y)$, while $r$ is the relative efficiency of the hidden economy relative to the regular economy. Both fitting parameters have clear meanings. Thus, the parameter $r$ gives a measure of the efficient use of the resources in hidden economy, that way shearing light on another dimension of the hidden economy that is particularly relevant for the sustainable development. The parameter $\mu$ is already often used elasticity of electricity consumption that can be compared to the results of various existing studies.

In the previous work we have shown that this method can be efficiently used for determination of the variations of hidden economy in small open economies, when using a limited set of data sources with outstanding precision. In this work we intend to make comparison of the results for Macedonia and Croatia in order to estimate the effectiveness of the method in such type of comparisons. In addition, our aim is to compare the results obtained by this method and the Lackó method adapted to the use for a single country and to discuss advantages and disadvantages of the two methods. Advantages and disadvantages of these two methods are to be discussed. Further development of the models based on energy consumptions indented to provide solutions avoiding the identified disadvantages are to be proposed.

\section{Data and inputs for sophisticated Kaufman and Kaliberda method} In this work we used data that are highly reliable and have high precision. These are data for total electricity consumption $(E)$ and GDP $(Y)$ produced by State Statistical Offices of Macedonia and Croatia, subsequently integrated in World Bank database (Databank). Therefore, the initial series of data are harmonized and reliable, thus providing a strong basis for correct determination of the quantities derived from these sets of data.

Since the method by itself provides relative quantities, calibration of the result is required using data from other studies. In our case, the results from the work (Schneider et al., 2010) are used, since they are estimated to be the most precise available.

The value of the size of hidden economy for the year 2001 has been set to be equal with the value obtained in (Schneider et al., 2010). Value of $r$ was determined under condition that the calculated in this work value of hidden economy for year 2005 is equal to the value obtained in (Schneider et al., 2010) for the same year.

Parameters of the sophisticated Kaufman and Kaliberda method obtained in this work are displayed in Table 1.

Table 1

Elasticity $(\mu)$ for electricity consumption with respect to GDP and relative efficiency of the hidden economy compared to the regular economy $(r)$

\begin{tabular}{lll}
\hline Country & Elasticity $(\boldsymbol{\mu})$ & Relative efficiency $(\boldsymbol{r})$ \\
\hline Macedonia & 0.348 & 0.460 \\
\hline Croatia & 0.480 & 0.550 \\
\hline
\end{tabular}

Source: Authors' work 


\section{Advantages of the sophisticated Kaufman and Kaliberda method over the standard one}

Detailed discussion on the construction of the sophisticated Kaufman and Kaliberda model and comparison with the standard one has been reported in reference (Novkovska et al., 2018). Brief explanation for these issues is provided below for the studied case of Macedonia and Croatia.

Standard method implicitly involves the assumption that the hidden and the regular economy have the same efficiency. Thus, the expression for the standard method is obtained as a particular case of the expression (4) for $r=1$. While determining the hidden economy based on this assumption (standard model), results displayed in Figure 2 are obtained. It is seen that this method gives huge oscillations, which are difficult to be considered as realistic. Particularly, the case of Macedonia shows enormous variations (from $30 \%$ to $60 \%$ ) in few years, which is markedly larger that the results obtained by other methods. Based on this we conclude that the sophisticated Kaufman and Kaliberda method is indispensable in order to determine correctly the size of hidden economy.

Long term evolution of the size of hidden economy by this method would require considering the variations with time of both parameters ( $\mu$ and $r$ ) used in the model. As we reported in (Novkovska et al., 2018), in the last few years a significant decrease of the elasticity $\mu$ is observed in some developed countries, such as is Switzerland. This change is explained by the increased volume of activities in espace (Elgin, 213; Gaspareniene et al., 2015).

Figure 2

Evolution of the hidden economy in Macedonia and Croatia, as obtained using the standard Kaufmann and Kaliberda method

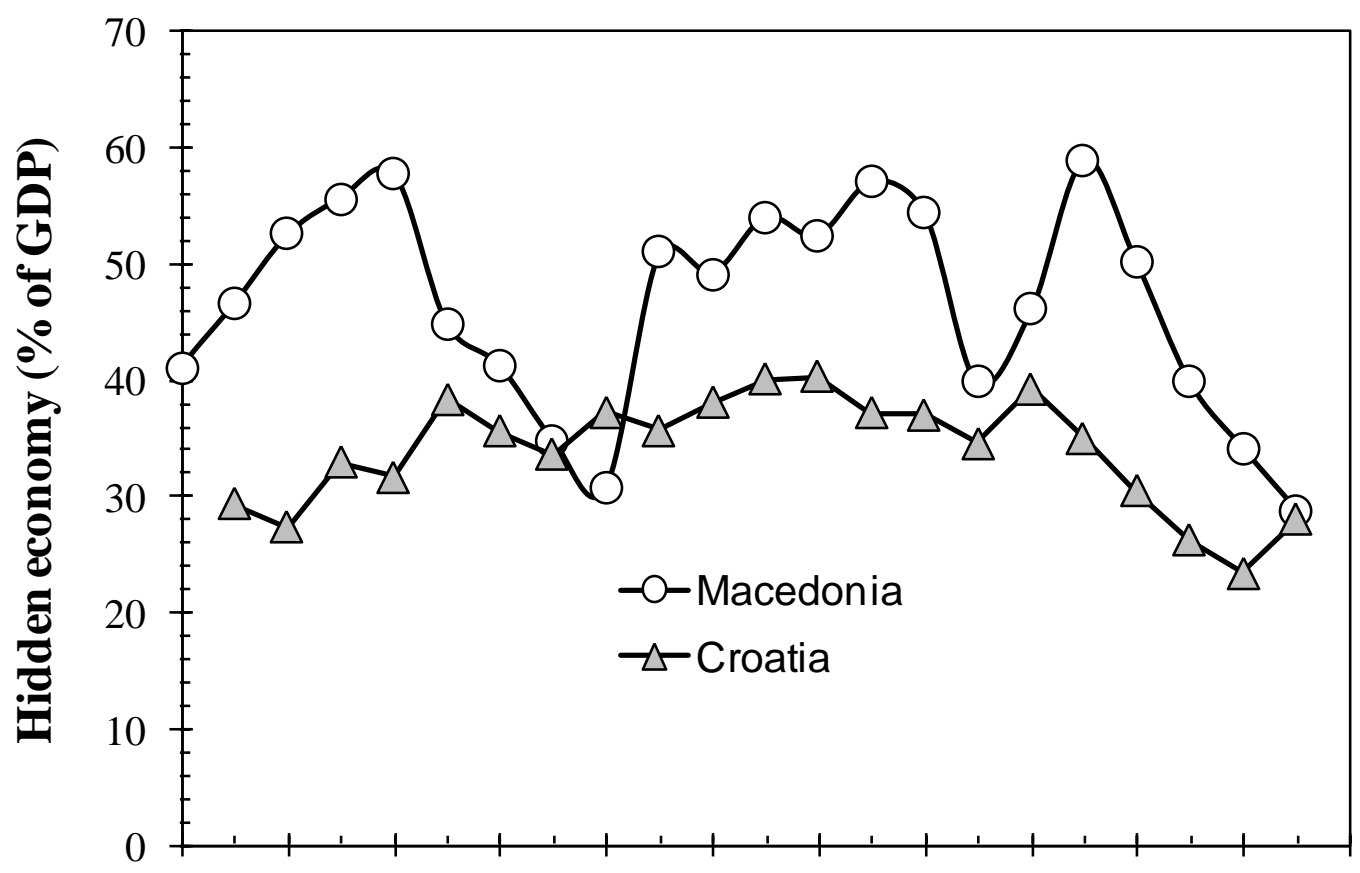

199419961998200020022004200620082010201220142016

\section{Year}

Source: Authors' work 
Such changes are not clearly observed in the case of less developed countries. Thus we, conclude that in the cases of Croatia and Macedonia for the period considered in the present work the model used here is acceptable without significant limitations. While studying evolution of hidden economy in future longer periods, variability of parameters has to be considered.

\section{Results}

Examples here are given for Macedonia, as a typical small open economy, and Croatia, as a good role-model for other states in Western Balkans..

\section{Results obtained by the Lackó method}

First, we show the results for the evolution of the hidden economy as a percentage of reported GDP in Macedonia since its independence in 1991, as it was obtained using the Lackó method (Novkovska, 2016a). It is seen (see Fig. 3) that there are several overshoots over the baseline of about $32 \%$. All the overshoots are identified and, except the first one, precisely quantised with Gaussians. Each of the Gaussians is described with a given magnitude, standard deviation and a central year (Fig. 3).

Figure 3

Evolution of the hidden economy in Macedonia since independence until year 2014, as obtained using the Lackó method

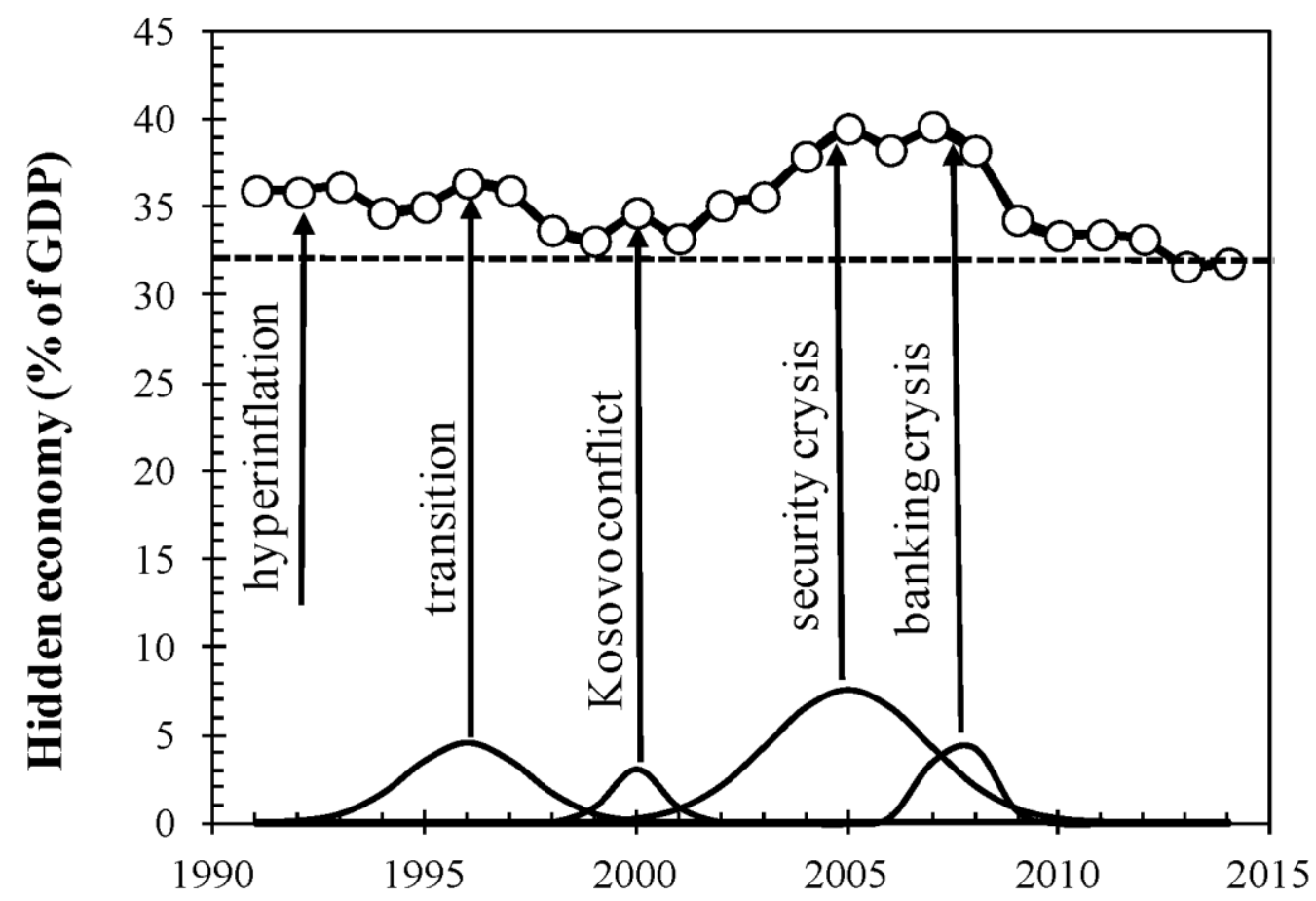

Year

Source: Novkovska (2016a).

First, the peak attributed to the hyperinflation in 1992 is located. It is difficult to be precisely quantised, since in the beginning of independence the data used are not of enough good quality. Then, economic transition from socialist to market economy, lasting roughly 6 years, have caused a temporal increase of about $4 \%$ in 
the hidden economy. Then, around year 2000, Kosovo conflict influenced shortly Macedonian economy. The most severe shock to the economy was produced by the security crisis (almost war) (Hislope, 2003). Since the crisis peaked in 2002, the damage to the economy lasted exceptionally long (roughly 8 years) and attained very high magnitude of about $8 \%$. The most recent peak, which is partially mixed with the previous one, is that for banking crisis at around year 2008.

It is to be noted that intensity and duration of the perturbations are bigger in the case of events taking place in the country (transition and security crisis) than in the case of events influencing the country from outside (Kosovo conflict and banking crisis).

\section{Results obtained by the sophisticated Kaufman and Kaliberda method}

Next we show comparison of the results for the evolution of hidden economy in Macedonia and Croatia, obtained by the sophisticated model based on Kaufmann and Kaliberda method. As it has been shown in (Novkovska et al., 2018), in a period close to the independence, the economy was extremely strongly disturbed by external factors. Thus, a big fluctuation in Croatia caused by the war in the beginning of nineties was obtained (size of hidden economy up to $45 \%$ ); later it sharply decreased. In Macedonia, in this period a sudden shock of hyperinflation caused a sharp increase around year 1992. After that, a similar behaviour for both countries has been observed, most probably due to similar conditions in which economy developed, as well as the condition from the past period. It is to be noted that the increase in the beginning progressed faster for Macedonia that for Croatia. At the end of this initial period, the hidden economy in Macedonia attained somehow higher level than in Croatia.

In order to obtain more relevant comparison between Macedonia and Croatia, we recalculated the sizes for hidden economies for the period 1994-2015. Data for the last two years that were not previously available are included in the calculations for this work. Results of the calculations are shown in Figure 4. For a reference, results obtained by Schneider et al. (2010) for a limited period (from 1999 to 2007) both for Macedonia and Croatia are shown along with the results obtained in this paper.

First to be noted is that results obtained in (Schneider et al., 2010) depict only the average size and the main trend for the given period. They do not reveal the fluctuations observed while using the model considered here. The main reason for this feature is panel approach without country-specific effects used in that work. As a result, the parameters extracted from the panel to reflect the average behaviour over the panel of countries considered. On the contrary to this, model used in this work do not filter in any way the fluctuations in the data arising from different origins. Thus, it involves various factors influencing rapid changes in both directions increase and decrease.

Second, it is observed that the size of hidden economy is systematically higher in Macedonia than in Croatia. Above finding can be connected to the general discovery that the size of hidden economy varies in opposite direction from that of the level of development of an economy. Many similarities between the evolution hidden economy between Macedonia and Croatia can be identified from Figure 4. Thus, a local maximum around year 2008 can be attributed in both cases to the banking crisis. Average rate of increase of the hidden economy for both countries in the period from 1994 to 2006 is practically the same. This is supposed to be connected to the same level of efficiency of hidden economy compared to the regular, as is seen from Table 1. Decrease of the size of hidden economy is observed 
for both countries. However, for Croatia this decrease started earlier and is substantially more intensive that in the case of Macedonia. Above finding can be attributed to the faster process of EU integration of Croatia. It is expected that the process of EU integration assisted improvement of the economy as a whole, thus removing many sources of the hidden economy that previously existed.

Finally, in both cases not satisfactory high substantial systematic reduction of the size of hidden economy was observed. Thus, the share of the hidden economy in total economy remained substantially high, attaining values above $30 \%$.

Figure 4

Evolution of the size of hidden economy in Croatia and Macedonia for the period 1994-2015, as obtained by the sophisticated Kaufmann and Kaliberda method

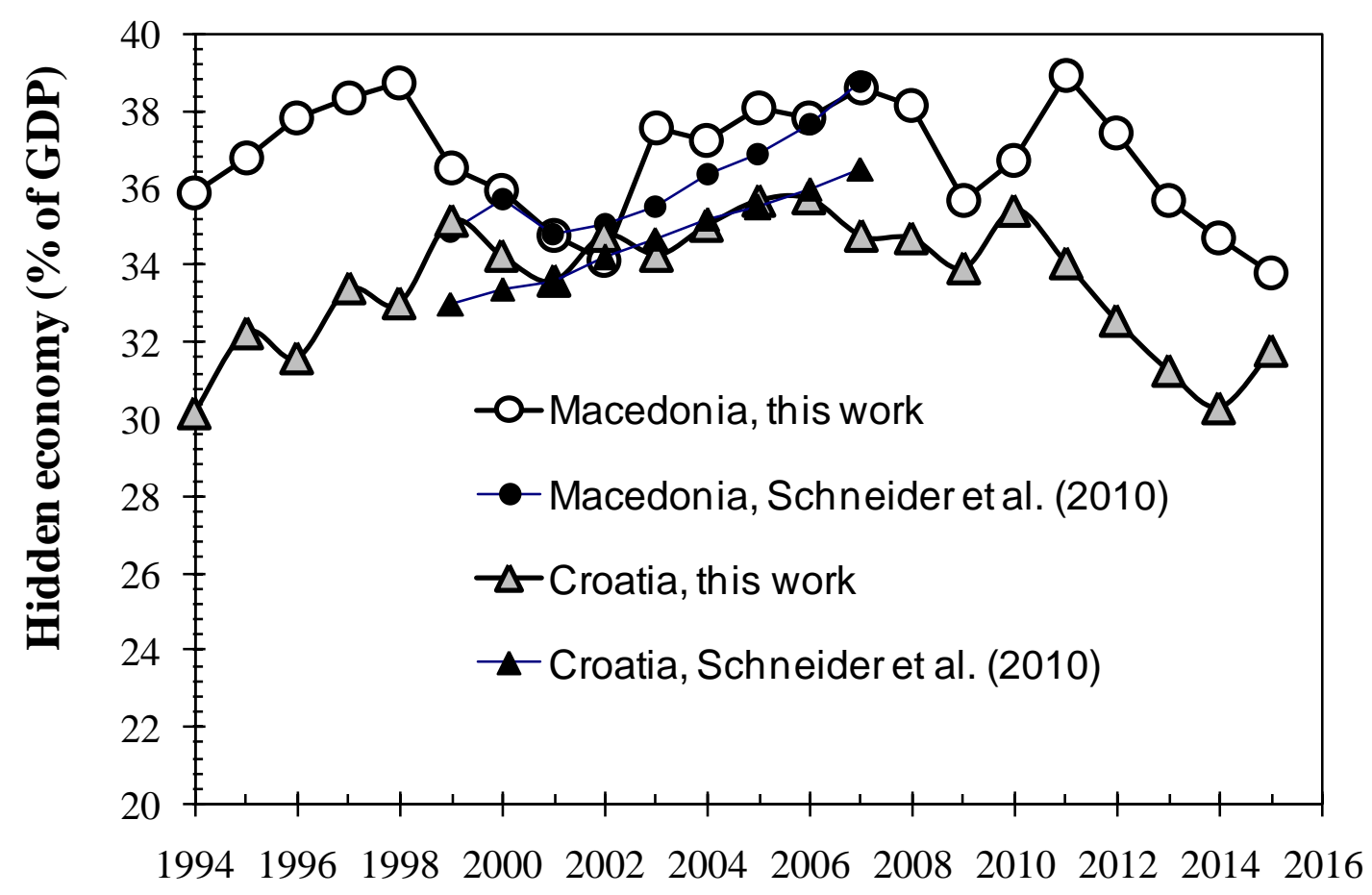

Year

Source: Authors' work

Based on our studies it can be affirmed that the method of determination of the size of hidden economy based on the energy consumption indicators can provide precise information on the evolution of hidden economy in small open economies, such as Western Balkan countries.

This period, from 1994 to 2015, for comparison of the hidden economies of Macedonia and Croatia was so chosen in order to emphasize the similarities in the case of crisis.

\section{Discussion}

Results obtained in this work for Macedonia and Croatia show that the methods based on connection between hidden economy and energy consumption can be particularly effective. They provide detailed picture of the variations of hidden economy with time and allow comparison of the studied phenomenon in different countries. 
Some differences are to be identified between the characteristics of the two methods used in this work. Country specifics adapted Lackó method provides precise picture of the variations that can be further analysed in finer details by refined analysis of the obtained temporal pattern. However, due to the use of many variables in the calculations, there is a risk of introducing substantial errors when some of the data for the indicators are not of enough good quality. From the other side, the main advantage of the sophisticated Kaufmann and Kaliberda method is its simplicity. Only two input variables are used and only two parameters are extracted from the input data. However, there are some disadvantages of the method, such as the substantial nonlinearity that could lead under some conditions to instabilities of the solution and hence to significant errors.

\section{Conclusion}

We have shown that model methods based on data for energy consumption are a useful tool for determination of the extent of hidden economy in open economies of limited size as is the case with the Western Balkan countries. In such kind of models, the quantities (indicators) from which the size of the hidden economy is determined are result of previously done precise measurements of quantifiable physical parameters. Besides, in these methods instead of being based on several ad hoc introduced hypotheses, known economic laws are used a basis of the expressions connecting the variables.

We put emphasize onKaufman and Kaliberda compact method, in which an analytical nonlinear expression with only two fitting parameters has been previously obtained, while using a single realistic hypothesis. It has been demonstrated that this method provides efficient description of the variation of hidden economy in crisis periods in Western Balkans. It appears that the same method can be effective for other countries and provide possibility to compare the intensities of hidden economies in these countries.

In this work the evolution of the size of hidden economy in Croatia and Macedonia for the period 1994-2015, as obtained by the sophisticated Kaufmann and Kaliberda method has been studied in details. A similar dynamics for both countries is noticed, as the result of transition of the economy. It is to be noted that the increase in the beginning of the 90-ties progressed faster for Macedonia than for Croatia. At the end of the observed period, the hidden economy achieved somehow higher level in Macedonia than in Croatia.

Methods used in this study allow one to obtain more details of the temporal patterns of hidden economy than typically used methods. However, there are limitations connected to the sensitivity of the results to various kinds of fluctuations. Thus, not only the real sharp changes are manifested in the result, but also some stochastic fluctuations could significantly influence the final result. Further studies are required in order to identify expected effect of stochastic fluctuations and errors in the input data on the results obtained by the methods using electricity consumption as indicator. After identifying the main sources of errors, methods of their reduction are to be proposed.

\section{References}

1. Ardizzi, G., Petraglia, C., Piacenza, M., Turati, G. (2014), "Measuring the underground economy with the currency demand approach: a reinterpretation of the methodology, with an application to Italy", Review of Income and Wealth, Vol. 60, No. 4, pp. 747-772.

2. Bejaković, P. (2017), "How to measure the unmeasurable: Project Grey developing capacities and capabilities for tackling undeclared work", Croatian Review of Economic, 
Business and Social Statistics, Vol. 3, No. 2, pp. 20-38.

3. Dumičić, K., Čibarić, I., Horvat, N. (2010), "The analysis of monetary transmission mechanism in Croatia using cointegration approach", Croatian Operational Research Review, Vol. 1, No. 1, pp. 210-220.

4. Dumicic, K., Palic, I., Sprajacek, P. (2015), "The role of external shocks in Croatia: block exogeneity SVAR approach", Ekonomski i socijalni razvoj, Vol. 2, No. 1, pp. 44-54.

5. Elgin, C. (2013), "Internet Usage and the shadow economy: evidence from panel data", Economic Systems, Vol. 37, No. 1, pp. 111-121.

6. Gaspareniene, L., Remeikiene, R., Schneider, F. G. (2015), "The factors of digital shadow consumption", Intellectual Economy, Vol. 9, No. 2, pp. 108-119.

7. Hislope, R. (2003), "Between a bad peace and a good war: insights and lessons from the almost-war in Macedonia", Ethnic and Racial Studies, Vol. 26, No. 1, pp. 129-151.

8. Kaufmann, D., Kaliberda, A. (1996), "Integrating the unofficial economy into the dynamics of post socialist economies: a framework of analyses and evidence", Policy Research Working Paper, No. 1691.

9. Lackó, M. (2011), "The hidden Economies of Visegrad Countries in International Comparison: A Household Electricity Approach", in Halpern, L., Wyplosz, C. (Eds.), Hungary: Towards a Market Economy, Cambridge University Press, Cambridge, pp. 128152.

10. Novkovska, B. (2016a), "The size of the hidden economy in Macedonia: Tendencies and challenges", in Proceedings of the ISCCRO: International Statistical Conference in Croatia, 05-06 May 2016, Zagreb, Croatia, pp. 182-189.

11. Novkovska, B. (2016b), "How Strongly the Hidden Economy of a Small Country can be Influenced by Drastic Events: Case of Macedonia", UTMS Journal of Economics, Vol. 7 , No. 2, pp. 187-195.

12. Novkovska, B., Novkovski, N. (2018), "Energy consumption and hidden economy in Macedonia: causes and responses", Journal of Policy Modelling, Vol. 40, No. 1, pp. 166181.

13. Ott, K. (2003), "The unofficial economy in Croatia 1990-2000", in Franičević, V., Kimura, H. (Eds.), Globalization, Democratization and Development: European and Japanese Views of Change in South East Europe, Masmedia, Zagreb.

14. Palić, I., Dumičić, K., Barbić, D. (2016), "The estimation of money demand elasticity: case of Croatia", in ICHSS 2016: International Conference on Humanities and Social Sciences.

15. Schneider, F. (2017), "Estimating a Shadow Economy: Results, Methods, Problems, and Open Questions", Open Economics, Vol. 1, No. 1, pp. 1-29.

16. Schneider, F., Buehn, A., Montenegro, C. E. (2010), "New Estimates for the Shadow Economies all over the World", International Economic Journal, Vol. 24, No. 4, pp. 443-461.

17. Takala, K. Viren, M. (2010), "Is cash used only in the shadow economy?", International Economic Journal, Vol. 24, No. 4, pp. 525-540.

18. Tanzi, V. (1980), "The underground Economy in the United States: Estimates and Implications", Banca Nationale del Lavoro Quartely Review, Vol. 135, No. 4, pp. 427-453.

19. Tanzi, V. (1999), "Uses and abuses of estimates of the underground economy", The Economic Journal, Vol. 109, No. 456, pp. 338-347.

20. Tanzi, V., Blejer, M. I. (1982), "Inflation, interest rate policy, and currency substitutions in developing economies: A discussion of some major issues", World Development, Vol. 10, No. 9, pp. 781-789.

21. Williams, C. C., Horodnic, I. A. (2015), "Evaluating the prevalence of the undeclared economy in Central and Eastern Europe: an institutional asymmetry perspective", European Journal of Industrial Relations, Vol. 21, No. 4, pp. 389-406.

22. Williams, C. C., Horodnic, I. A. (2016), "Tackling the undeclared economy in the European Union: an evaluation of the tax morale approach", Industrial Relations Journal, Vol. 47, No. 4, pp. 322-340. 


\section{About the authors}

Blagica Novkovska, PhD, is an Assistant Professor at the Faculty of Economics, University of Tourism and Management in Skopje. She offers more than 25 years of experience with official statistics, from which 10 years as General Director of the State Statistical Office. She is elected member of the International Statistical Institute and member of several international associations. She leaded more than 10 EU funded projects in the field of official statistics. She authored 4 books and more than 40 research papers on: macroeconomic modelling, clustering, quality management, sustainable development, regional development and labour economics. The author can be contacted at b.novkovska@utms.edu.mk.

Ksenija Dumičić, PhD, Full Tenured Professor at the Department of Statistics, Faculty of Economics and Business, University of Zagreb, specialized at the Institute for Social Research at University of Michigan, focusing on survey sampling, SQC and business statistics. She is founder and the leader of the first statistical postgraduate studies in Croatia. She led and participated in many projects granted by Ministry of Science in Croatia, World Bank, UNICEF, WHO, EU etc. She is President of Croatian Statistical Association, Editors-in-Chief for Croatian Review of Economic, Business and Social Statistics, founder of the International Statistical Conference in Croatia (ISCCRO), Elected Member at the International Statistical Institute (ISI), contributing to the IASS, IASE, WSC at the ISI, and member of the Royal Statistical Society. She published more than 180 publications. The author can be contacted at kdumicic@net.efzg.hr. 